\title{
Gastrointestinal Motility Changes and Myenteric Plexus Alterations in Spontaneously Diabetic Biobreeding Rats
}

\author{
Ingrid Demedts, ${ }^{1}$ Tatsuhiro Masaoka, ${ }^{1}$ Sebastien Kindt, ${ }^{1}$ Gert De Hertogh, ${ }^{2}$ Karel Geboes, ${ }^{2}$ Ricard Farré, ${ }^{1}$ Pieter Vanden Berghe \\ and Jan Tack $^{1 *}$ \\ ${ }^{1}$ Translational Research Center for Gastrointestinal Disorders and ${ }^{2}$ Department of Pathology, University of Leuven, Leuven, Belgium
}

\begin{abstract}
Background/Aims
Type 1 diabetes is often accompanied by gastrointestinal motility disturbances. Vagal neuropathy, hyperglycemia, and alterations in the myenteric plexus have been proposed as underlying mechanism. We therefore studied the relationship between vagal function, gastrointestinal motiliy and characteristics of the enteric nervous system in the biobreeding (BB) rat known as model for spontaneous type 1 diabetes.
\end{abstract}

\section{Methods}

Gastric emptying breath test, small intestinal electromyography, relative risk-interval variability, histology and immunohistochemistry on antral and jejunal segments were performed at 1,8 and 16 weeks after diabetes onset and on age-matched controls.

\section{Results}

We observed no consistent changes in relative risk-interval variability and gastric emptying rate. There was however, a loss of phases 3 with longer duration of diabetes on small intestinal electromyography. We found a progressive decrease of nitrergic neurons in the myenteric plexus of antrum and jejunum, while numbers of cholinergic nerve were not altered. In addition, a transient inflammatory infiltrate in jejunal wall was found in spontaneous diabetic BB rats at 8 weeks of diabetes.

\section{Conclusions}

In diabetic BB rats, altered small intestinal motor control associated with a loss of myenteric nitric oxide synthase expression occurs, which does not depend on hyperglycemia or vagal dysfunction, and which is preceded by transient intestinal inflammation.

(J Neurogastroenterol Motil 2013;19:161-170)

\section{Key Words}

Diabetes mellitus; Electromyography; Enteric nervous system; Gastric empyting; Rats, inbred BB

Received: August 27, 2012 Revised: December 17, 2012 Accepted: January 2, 2013

(c) This is an Open Access article distributed under the terms of the Creative Commons Attribution Non-Commercial License (http://creativecommons. org/licenses/by-nc/3.0) which permits unrestricted non-commercial use, distribution, and reproduction in any medium, provided the original work is properly cited.

*Correspondence: Jan Tack, MD, PhD

Translational Research Center for Gastrointestinal Disorders, University of Leuven, 3000 Leuven, Belgium

Tel: +32-16-34-5761, Fax: +32-16-34-5939, E-mail: jan.tack@med.kuleuven.be

Financial support: This study was supported by a grant from FWO Belgium and by a Methusalem grant from University of Leuven to Jan Tack. Conflicts of interest: None.

Author contributions: Ingrid Demedts performed experiments, analysed and interpreted data and wrote manuscript. Tatsuhiro Masaoka, Sebastien Kindt, Gert De Hertogh and Karel Geboes performed experiments, analysed and interpreted data and reviewed manuscript. Ricard Farré interpreted data and reviewed manuscript. Pieter Vanden Berghe designed study, interpreted data and reviewed manuscript. Jan Tack designed study, provided funding, interpreted data and reviewed manuscript. 


\section{Introduction}

Diabetes mellitus in humans is frequently associated with gastrointestinal motility disorders such as delayed gastric emptying, constipation and diarrhea. ${ }^{1,2}$ In animal models of diabetes, gastrointestinal motility disorders have also been described. ${ }^{3-5}$ The abnormalities of motor control in diabetes are thought to originate at least in part from visceral autonomous neuropathy, ${ }^{2}$ more specifically from changes in vagal innervations. ${ }^{3}$ On the other hand, abnormalities of the intrinsic enteric nervous system have also been reported, and they may also contribute to abnormal motor control. Most of these studies were carried out in animals where diabetes was induced by streptozotocin, ${ }^{4,6-15}$ which is not devoid of some direct neurotoxic properties. ${ }^{16}$ Spontaneously diabetic biobreeding (BB) rats ${ }^{17}$ are considered as a useful model for human type 1 diabetes as they develop a pancreatic infiltration with destruction of the insulin producing beta cells around 2-3 months of age. More recent studies also reported changes in neurotransmitter content of the myenteric plexus in spontaneously diabetic BB rats. ${ }^{18,19}$ Assessment of smooth muscle contractility in vitro in response to electrical field stimulation and ligand application confirmed altered neural motor control. ${ }^{7,18-20}$ In the jejunum of spontaneously diabetic BB rats, decreased nitrergic motor control and decreased neuronal nitric oxide synthase (nNOS) protein expression occur, while purinergic transmission is unaffected. ${ }^{19}$ However, the time-course of these alterations has not been studied in detail, and it is unclear to which extent gastrointestinal motility in vivo is affected, as very few studies have been devoted to motility measurements in these models. Furthermore, conflicting reports exist on the influence of blood glucose levels on gastric emptying: both hypoglycemia ${ }^{21}$ and hyperglycemia ${ }^{22}$ have been reported to accelerate gastric emptying and conversely, hyperglycemia was also reported to induce delayed gastric emptying. ${ }^{23}$

In this study we examined in vivo upper gastrointestinal motility and changes in neurotransmitter content of the myenteric plexus in spontaneously diabetic BB rats. We correlated these changes to measurements of relative risk (RR)-interval variability $^{24-26}$ to assess diabetic neuropathy of the vagal nerve. Gastric emptying of semi-solids and small intestinal electromyography (EMG) were used to monitor motility changes. Immunohistochemistry was used to assess changes in neurotransmitter content in the myenteric plexus. We measured RR-interval variability to determine whether vagal neuropathy was present. Since an in- flammatory infiltration in the colonic wall in $\mathrm{BB}$ rats has been reported $^{27,28}$ we also performed myeloperoxidase (MPO) activity measurements and histologic examinations to detect such an infiltrate in the upper gastrointestinal tract.

\section{Materials and Methods}

\section{Biobreeding Rats}

In the $\mathrm{BB}$ rat breeding colony of our institution, approximately $2 / 3$ of the rats develop diabetes around the third month of life ( $93 \pm 3$ days). We screened for development of diabetes by glycosuria testing (Clinistix ${ }^{\circledR}$; Bayer, Boca Raton, FL, USA) twice a week. Diabetic rats received insulin according to 2 regimens, maintaining either chronic hyperglycemia or near-normoglycemia. After development of glycosuria, confirmation of the diagnosis was made by the measurement of hyperglycemia of $>200 \mathrm{mg} / \mathrm{dL}$ (Glucometer Elite ${ }^{\mathbb{R}}$; Bayer). After diagnosing diabetes, long-acting insulin (Ultratard ${ }^{\circledR}$; Novo Nordisk, Bagsvørd, Denmark) was administered subcutaneously once daily to maintain blood glucose levels between 300 and $400 \mathrm{mg} / \mathrm{dL}$, and to prevent ketonuria (Ketostix ${ }^{\circledR}$; Bayer). Non-diabetic littermates were used as sex- and age-matched controls. Although chronic glycemia in diabetic rats was significantly higher than in controls, fasting glycemias at the time of acute experiments were often in the normal range. To determine more clearly the effect of chronic hyperglycemia on the EMG findings, a subgroup of rats were treated by subcutaneously implanting small insulin coated rods (LinPlant, Linshin Canada Inc., Toronto, Ontario, Canada). These rods, which release a continuous amount of insulin, result in chronic near-normoglycemia. All procedures were approved by the Animal Care and Use Committee of the University of Leuven.

\section{Gastric Emptying}

After 1, 8 and 16 weeks of diabetes, animals underwent gastric emptying studies using a ${ }^{14} \mathrm{C}$-octanoic acid breath test, which has been described elsewhere. ${ }^{29}$ Briefly, after an overnight fast, rats ate a semi-solid test meal doped with ${ }^{14} \mathrm{C}$-octanoic acid, which is absorbed into the small intestine, but not the stomach. Octanoic acid is preferentially metabolized in the liver to form ${ }^{14} \mathrm{CO}_{2}$, which is then exhaled. Immediately after ingestion of the test meal, animals were placed in an airtight container with continuous airflow. The ${ }^{14} \mathrm{CO}_{2}$ in the outgoing air was measured and fitted to an excretion curve. $T_{1 / 2}$ was calculated and compared between diabetic and control rats. 


\section{Small Intestinal Electromyography}

One or two days after the breath test, animals were prepared for small intestinal EMG testing. After laparotomy, 4 bipolar electrodes (Nichrome wire, $80 \mu \mathrm{m}$ diameter, insulated except at the tip) were attached at regular intervals to the jejunum ${ }^{30,31}$ and tunneled subcutaneously. The electrodes, protected by a metal wire coil fastened to the skin, were led outside the cage. After the operation, all rats moved freely in individual cages and had unrestricted access to food and water. One week later, all rats had fully recovered. After an overnight fast, small intestinal EMG signals were recorded and integrated every 10 seconds for at least one hour, using a similar method as previously reported. $^{31-33}$ The signals were digitized (WINDAQ; DATAQ Instruments Inc., Akron, OH, USA and Microsoft Corp., Redmond, WA, USA) and analyzed semi-automatically.

Activity fronts were defined as periods of at least one minute, in which the integrated signal was raised above a set threshold. ${ }^{31}$ Progression over the electrodes was checked visually, as were the phases 1 (absence of activity for at least 30 seconds, within 3 minutes after the end of an activity front). Phase 3 was characterized by (1) an aborally migrating activity front and (2) which was followed by a phase 1 . After EMG recordings, animals were sacrificed, the exact locations of electrodes were determined and the jejunum was removed.

\section{Relative Risk-interval Variability}

The RR-interval, the time between 2 successive R-spikes in the QRS complex, is determined by heart rate. Heart rate normally displays a respiration-related variation, which is decreased in autonomic nervous system dysfunction. ${ }^{23,24}$ Thus, loss of
RR-interval variability can be used to look for autonomous neuropathy. In this study, 3 subcutaneous thoracic electrodes were implanted, tunneled subcutaneously and led outside the cage. After a week, electrocardiogram signals were recorded and RR-interval variability was determined. Using spectral power analysis and an algorithm developed in our institution, ${ }^{25}$ we determined the low frequency/high frequency ratio (LF/HF ratio) of RR-intervals. The low frequencies $(0.195$ to $0.740 \mathrm{~Hz})$ are predominantly dependent on sympathetic input; the high frequencies (between 0.78 and $2.50 \mathrm{~Hz}$ ) are more under parasympathetic (vagal) control. In autonomous diabetic neuropathy, especially the HF component is reduced, resulting in a higher LF/HF ratio. ${ }^{23,24}$

\section{Immunohistochemistry}

After gastric emptying test, small intestinal EMG and electrocardiogram recording, animals were sacrificed and the small intestine and stomach were removed out for histochemical and immunohistochemical studies of the myenteric plexus. Prior to the labeling experiments, the absence of non-specific cross-reactions between antisera, and the correspondence between nNOS-immunoreactivity and nicotinamide adenine dinucleotide phosphatase (NADPH) diaphorase reactivity were confirmed. Triple labeling immunohistochemistry (neuron specific enolase [NSE], choline acetyltransferase [ChAT] and nNOS) evaluated the neurotransmitter content of the myenteric neurons: longitudinal muscle-myenteric plexus preparations (LMMPP) of jejunum and the antrum were placed 2-3 hours in blocking buffer, 48 hours in primary antibody buffer and 2-3 hours in fluorescence labeled secondary antibodies buffer (Table 1). After mounting

Table 1. List of Primary and Secondary Antisera Used in Staining of the Myenteric Plexus

\begin{tabular}{|c|c|c|c|c|c|c|}
\hline \multicolumn{7}{|c|}{ Primary antisera } \\
\hline Antigen & \multicolumn{2}{|c|}{ Antigen function } & Host & Type & Dilution & Source \\
\hline NSE & \multicolumn{2}{|c|}{ Pan-neuronal marker } & Rabbit & Polyclonal & $1: 1000-1: 3000$ & Polysciences, Warrington, USA \\
\hline ChAT & \multicolumn{2}{|c|}{ Excitatory NT production } & Goat & Polyclonal & $1: 100$ & Chemicon Int. Inc., Temecula, USA \\
\hline nNOS & \multicolumn{2}{|c|}{ Inhibitory NT production } & Mouse & Monoclonal & $1: 150$ & Transduction Lab., Lexington, USA \\
\hline \multicolumn{7}{|c|}{ Secondary antisera } \\
\hline Antigen & Label & Host & Type & \multicolumn{2}{|c|}{ Dilution } & Source \\
\hline Rabbit IgG & AMCA & Donkey & Polyclonal & \multicolumn{2}{|c|}{$1: 250-1: 500$} & on ImmunoRes. Lab., West Grove, USA \\
\hline Goat IgG & FITC & Donkey & Polyclonal & \multicolumn{2}{|c|}{$1: 50$} & \multirow{2}{*}{$\begin{array}{l}\text { Jackson ImmunoRes. Lab., West Grove, USA } \\
\text { Jackson ImmunoRes. Lab., West Grove, USA }\end{array}$} \\
\hline Mouse IgG & Texas red & Donkey & Polyclonal & $1: 500$ & $\mathrm{Jacl}$ & \\
\hline
\end{tabular}

NSE, neuron specific enolase; ChAT, choline acetyl transferase; NT, neurotransmitter; nNOS, neuronal nitric oxide synthase; AMCA, aminomethylcoumarin; FITC, fluorescein isothiocyanate.

The used anti-nNOS does not react with inducible NOS. 
the LMMPP on glass slides, immunoreactive (IR) cell bodies were counted in 100 jejunal or antral myenteric ganglia for both diabetic and control groups. Nerve cells were identified by NSE immunoreactivity.

\section{Histology and Assessment of Inflammation}

A segment of jejunum was placed in $4 \%$ formaldehyde for at least 24 hours, then embedded in paraffin. H\&E staining was performed on full thickness slides. Signs of inflammation were checked light optically by an experienced pathologist.

MPO activity was measured as previously described. ${ }^{34}$ Briefly, the mucosa was separated from the underlying layers by blunted dissection in $0.9 \% \mathrm{NaCl}$ and immediately snap-frozen in liquid nitrogen. After homogenization of the tissue in Hexadecyltrimethylammonium bromide buffer, the homogenate was centrifuged $\left(12,500 \mathrm{~g}, 4^{\circ} \mathrm{C}, 30\right.$ minutes) and supernatant MPO activity was measured spectrophotometrically $(\lambda=460 \mathrm{~nm})$ after addition of $\mathrm{H}_{2} \mathrm{O}_{2}$ and $\mathrm{O}$-dianisidine hydrochloride. Results were expressed in units/mg tissue.

\section{Statistical Methods}

Results are shown as mean \pm SEM. ANOVA (analysis of variance), Student's $t$, Chi-square and Fisher exact test were performed using Microsoft Excel 97 or GraphPad InStat 3.00. Bonferoni's correction was used for multiple testing.

\section{Results}

\section{Animal Cohorts and Control of Diabetes}

The mean glycemia of rats with insulin rod implants was 88 $\pm 15 \mathrm{mg} / \mathrm{dL}$, which was comparable to control rats $(94 \pm 6$

Table 2. Age and Food Intake at Gastric Emptying Testing in Control and Diabetic Biobreeding Rats at Various Time Points

\begin{tabular}{lrll}
\hline & Control & Diabetes & Student's $t$ test \\
\hline Age at test (days) & & & \\
Week 1 & $99 \pm 4$ & $112 \pm 13$ & NS \\
Week 8 & $142 \pm 3$ & $158 \pm 12$ & NS \\
Week 16 & $213 \pm 6$ & $207 \pm 6$ & NS \\
Food ingested & & & \\
(mg/100 g body weight) & & & \\
Week 1 & $195 \pm 9$ & $172 \pm 8$ & NS \\
Week 8 & $189 \pm 5$ & $200 \pm 4$ & NS \\
Week 16 & $189 \pm 9$ & $166 \pm 13$ & NS \\
ANOVA & NS & NS & \\
\hline
\end{tabular}

$\mathrm{mg} / \mathrm{dL}, \mathrm{NS})$; and significantly lower than insulin-injected rats (319 $\pm 16, P<0.001)$. All other characteristics (age at onset of diabetes, duration of diabetes and location of electrodes) did not differ between insulin rod-implanted and insulin-injected rats. It should be noted that although chronic glycemia in diabetic rats was significantly higher than in controls, fasting glycemias at the time of acute experiments in this study were within the same range ( $97 \pm 15$ vs. $73 \pm 3 \mathrm{mg} / \mathrm{dL}, \mathrm{NS}$ ).

\section{Gastric Emptying}

Gastric emptying breath tests were performed in 27 diabetic insulin-injected animals and 35 non-diabetic controls at 1, 8 and 16 weeks. Both groups were age and sex-matched and the amount of food ingested did not differ at any of the 3 time points (Table 2). No major differences in gastric emptying rate were observed (Fig. 1). Gastric emptying rate did not differ between diabetic and control rats at $1\left(\mathrm{~T}_{1 / 2} 50.6 \pm 3.8\right.$ vs. $49.6 \pm 2.8 \mathrm{mi}-$ nutes, NS), 8 ( $\mathrm{T}_{1 / 2} 43.6 \pm 2.3$ vs. $34.1 \pm 2.7$ minutes, NS) and 16 weeks ( $\mathrm{T}_{1 / 2} 55.5 \pm 15.4$ vs. $57.9 \pm 9.5$ minutes, NS). Gastric emptying in control rats at 8 weeks was significantly faster than in diabetic rats at 8 weeks and than control rats at other time points, but this was no longer significant after Bonferroni correction for multiple testing.

\section{Small Intestinal Electromyography}

Small intestinal EMG was performed in 22 diabetic animals and 18 non-diabetic controls. The location of the electrodes did not differ between the 2 groups. The first electrode was located $13.0 \pm 0.3 \mathrm{~cm}$ distal to the pylorus, the second was located at 4.4

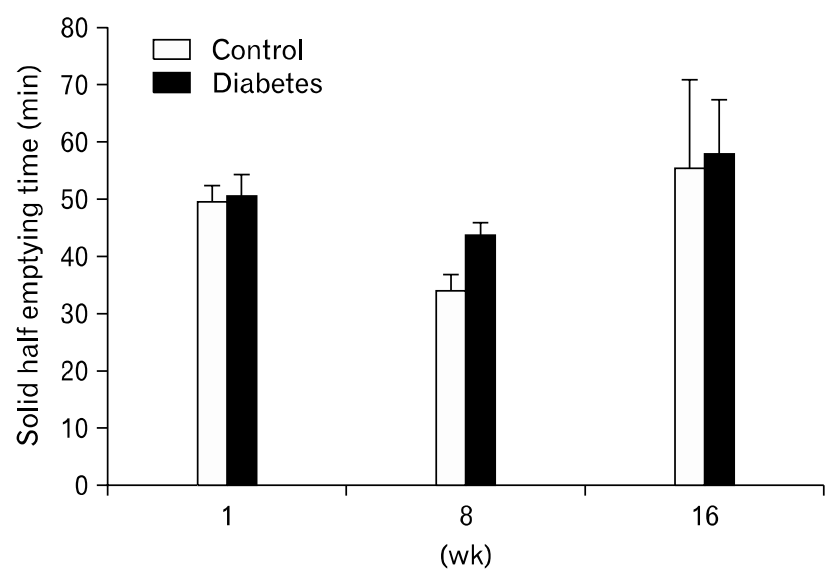

Figure 1. Gastric half emptying times for semi-solids in diabetic and sex- and age-matched control rats at 1,8 and 16 weeks after onset of diabetes. No significant differences occurred between both groups at any time point. 
$\pm 0.3 \mathrm{~cm}$ more distally, and the third and fourth electrodes followed at distances of $4.4 \pm 0.2$ and $4.2 \pm 0.2 \mathrm{~cm}$, respectively.

The number and duration of activity fronts and phases $3 \mathrm{did}$ not differ significantly between both groups at individual time points (Table 3). However, after 1 and 8 weeks of diabetes, the proportion of propagated activity fronts was significantly lower than in control rats (43/61 vs. $61 / 71$ and $48 / 85$ vs. $39 / 53$, respectively, both $P<0.05$ ), but this was no longer significant after 16 weeks ( $30 / 42$ vs. $15 / 22$, respectively, NS). Over time, the number of phases 3 decreased and the interval between phases 3 lengthened significantly in the diabetic group, but not in the control group (Fig. 2). The number of phases 3 per hour did not differ significantly between diabetic and control rats at $1(4.9 \pm 1.7$ vs. $3.8 \pm 1.3, \mathrm{NS}), 8(2.2 \pm 0.6$ vs. $3.5 \pm 0.8, \mathrm{NS})$ and 16 weeks $(1.8 \pm 1.0$ vs. $2.5 \pm 1.0$, NS). Similarly, duration of activity fronts shortened significantly over time in control rats, but not in diabetic rats (Table 3 ).

Compared to rats receiving daily subcutaneous insulin injections, the subgroup of 8 rats in which glycemia was tightly controlled with insulin rod implants, did not differ in number (7.5 \pm 2.2 per hour, NS), duration ( $3.5 \pm 0.3$ minutes, NS), proportion of activity fronts that were propagated $(26 / 39, \mathrm{NS})$ and number of phases 3 ( $3 \pm 2$ per hour, NS).

\section{Relative Risk-interval Variability}

RR-interval measurements were performed in 6 insulin- treated diabetic and 5 control animals, at 1 and 16 weeks. LF/HF ratio did not differ significantly between diabetic and control animals after 1 and 16 weeks $(0.53 \pm 0.26$ vs. $0.58 \pm 0.08$ and $0.33 \pm$ 0.16 vs. $1.04 \pm 0.13$, respectively, both NS). In the diabetic

Table 3. Small Intestinal Electromyography Results

\begin{tabular}{lccc}
\hline & Control & Diabetes & $\begin{array}{c}\text { Student's } \\
t \text { test }\end{array}$ \\
\hline $\begin{array}{l}\text { Number of activity fronts } \\
\text { per hour }\end{array}$ & & \\
$\quad$ Week 1 & $9.8 \pm 1.5$ & $9.9 \pm 1.3$ & NS \\
Week 8 & $10.7 \pm 2.6$ & $9.2 \pm 0.9$ & NS \\
Week 16 & $9.3 \pm 1.1$ & $7.5 \pm 2.2$ & NS \\
ANOVA & NS & NS & \\
Duration of activity fronts & & & \\
(min) & & & \\
Week 1 & $3.5 \pm 0.3$ & $3.4 \pm 0.1$ & NS \\
Week 8 & $2.8 \pm 0.2$ & $3.2 \pm 0.2$ & NS \\
Week 16 & $2.6 \pm 0.3$ & $3.4 \pm 0.4$ & NS \\
ANOVA & $P<0.05$ & NS & \\
\hline
\end{tabular}

group, there was no alteration over time in the $\mathrm{LF} / \mathrm{HF}$ ratio $(0.53$ $\pm 0.26,0.51 \pm 0.13$ and $0.33 \pm 0.16, \mathrm{NS})$. The overall LF/HF ratio in diabetic animals was $0.47 \pm 0.11$ and $0.73 \pm 0.11(\mathrm{NS})$ in control animals.

\section{Jejunal Inflammation}

After one week of diabetes, light optical imaging and leukocyte antibodies revealed only occasional, submucosally localized, inflammatory cells. After 8 weeks of diabetes, thickening of the muscle layers, and prominent transmural inflammatory infiltrate were apparent. Inflammatory cells could be seen adjacent to ganglion cells in both of submucoal and myenteric plexuses (Fig. 3). After 16 weeks, the inflammation had subsided again, with only the occasional presence of submucosal inflammatory cells. Thickening of the muscle layers was no longer present. MPO activity was increased after 8 weeks of diabetes compared to controls $(6.4 \pm 2.1$ vs. $1.3 \pm 0.2 \mathrm{U} / \mathrm{mg}, P<0.05)$. No significant difference was found at 16 weeks $(1.6 \pm 0.4$ vs. $1.3 \pm 0.3 \mathrm{U} / \mathrm{mg}$, NS).
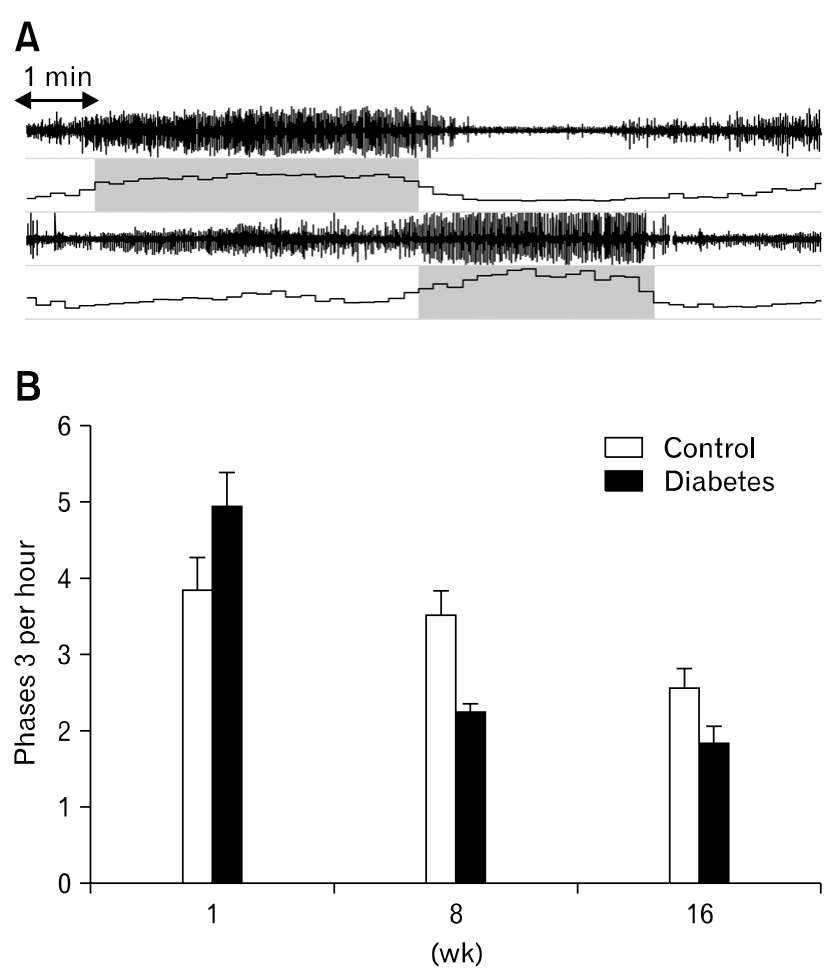

Figure 2. (A) Example of semi-automatic analysis of small intestinal electromyography of 2 consecutive electrodes (E1 and E2). Activity fronts $(\square)$ are defined as periods of at least 1 minute, in which the integrated signal is raised above the set threshold. (B) Number of phases 3 per hour in diabetic and sex- and age-matched control rats at 1,8 and 16 weeks after onset of diabetes. Over time, the number of phases 3 decreased significantly in the diabetic group. 


\section{Immunohistochemistry}

In the myenteric plexus of the gastric antrum, the number of

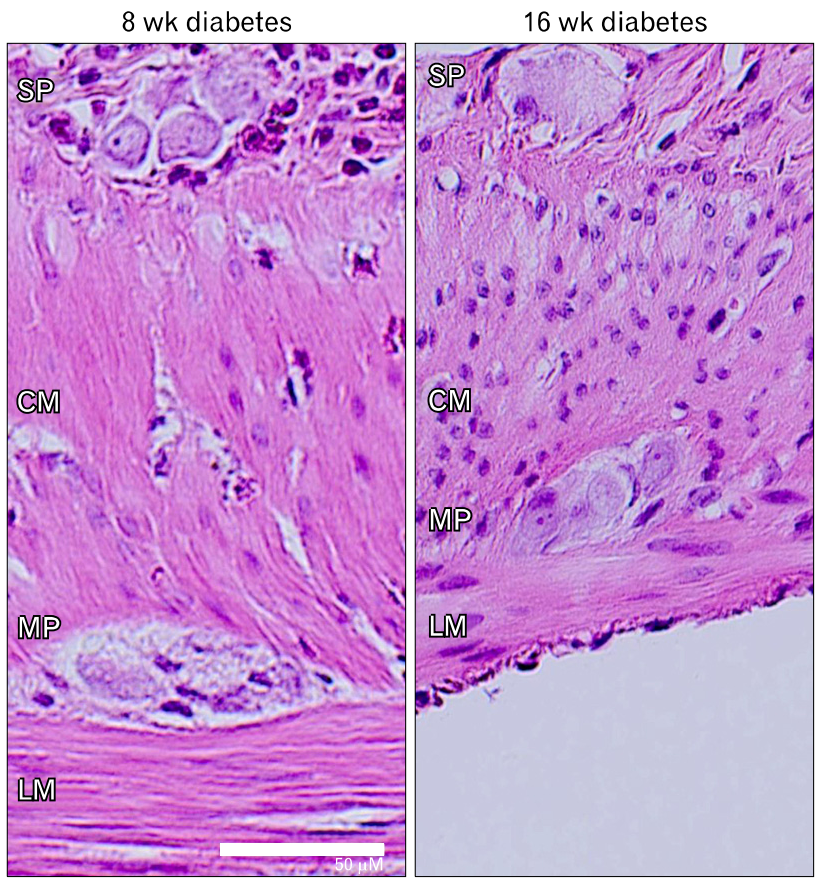

Figure 3. Representative image of 8 and 16 weeks diabetic rat by $\mathrm{H} \& \mathrm{E}$ staining. Eight weeks after onset of diabetes, infiltration of polymorphonuclear leukocyte cells into enteric nervous system (SP, submucosal plexus; MP, myenteric plexus) was present with thickening of the muscular layers (CM, circular muscle; LM, longitudinal muscle). However, 16 weeks after onset of diabetes, no inflammatory infiltrate was seen. Scale bar $=50 \mu \mathrm{m}$.
NSE-IR neurons per ganglion did not differ significantly between diabetic rats and matched controls after 1, 8 and 16 weeks of onset of diabetes. At 16 weeks, the number of ChAT-IR neurons per ganglion was higher in diabetic animals, but this was no longer significant after correction for multiple testing (Table 4). Over time, antral nNOS-IR, but not NSE- and ChAT-IR, decreased significantly in both groups $(P<0.005$ for diabetes, $P<0.001$ in controls). Counts of nNOS myenteric neurons were lower in diabetic than in control animals at every time point (Fig. 4). In the myenteric plexus of the jejunum, the number of NSE-IR and ChAT-IR did not differ between diabetic and control animal. Over time, jejunal NSE- and ChAT-IR did not vary significantly in either group (Table 4). However, nNOS-IR was significantly decreased at week 8 and 16 (Fig. 4). The number of nitrergic neurons per ganglion in the antrum was significantly lower in diabetic animals compared to controls at $1(6.1 \pm 0.4$ vs. $8.1 \pm 0.4, P<0.001), 8(4.1 \pm 0.3$ vs. $5.2 \pm 0.4, P<0.05)$ and 16 weeks $(2.9 \pm 0.2$ vs. $5.5 \pm 0.3, P<0.001)$ between both groups. The number jejunal nitrergic neurons was significantly lower in diabetic animals compared to controls at 8 (3.0 \pm 0.3 vs. $3.7 \pm 0.3, P=0.05)$ and $16(2.3 \pm 0.2$ vs. $3.4 \pm 0.3, P<0.01)$ but not at 1 week $(6.6 \pm 0.4$ vs. $7.3 \pm 0.4, \mathrm{NS})$. As in the antrum, jejunal nNOS-IR decreased significantly over time in both diabetic and control animals $(P<0.001)$. The number of nitrergic neurons was not significantly correlated to gastric emptying times, activity fronts or phases 3 , except for a significant correlation between the number of phases 3 and nitrergic neuron counts at week 16 in diabetic rats $(\mathrm{R}=0.490, P<0.05)$.

Table 4. Immunohistochemistry

\begin{tabular}{|c|c|c|c|c|c|c|}
\hline \multirow{2}{*}{$\begin{array}{c}\text { NSE } \\
\text { (cells per ganglion) }\end{array}$} & \multicolumn{3}{|c|}{ Antrum } & \multicolumn{3}{|c|}{ Jejunum } \\
\hline & Control & Diabetes & Student's $t$ test & Control & Diabetes & Student's $t$ test \\
\hline Week 1 & $34.0 \pm 0.7$ & $35.1 \pm 0.9$ & NS & $28.9 \pm 0.6$ & $31.4 \pm 0.8$ & NS \\
\hline Week 8 & $33.4 \pm 0.6$ & $35.7 \pm 1.0$ & NS & $30.5 \pm 0.9$ & $30.2 \pm 0.7$ & NS \\
\hline Week 16 & $34.6 \pm 0.8$ & $37.1 \pm 0.9$ & NS & $31.4 \pm 0.8$ & $32.3 \pm 0.8$ & NS \\
\hline ANOVA & NS & NS & & NS & NS & \\
\hline \multirow{2}{*}{$\begin{array}{c}\text { ChAT } \\
\text { (cells per ganglion) }\end{array}$} & \multicolumn{3}{|c|}{ Antrum } & \multicolumn{3}{|c|}{ Jejunum } \\
\hline & Control & Diabetes & Student's $t$ test & Control & Diabetes & Student's $t$ test \\
\hline Week 1 & $30.1 \pm 0.7$ & $31.8 \pm 0.9$ & NS & $26.3 \pm 0.6$ & $31.5 \pm 2.9$ & NS \\
\hline Week 8 & $30.5 \pm 0.6$ & $32.9 \pm 1.0$ & NS & $27.6 \pm 1.0$ & $27.6 \pm 0.7$ & NS \\
\hline Week 16 & $30.6 \pm 0.8$ & $34.2 \pm 0.9$ & NS & $28.9 \pm 0.7$ & $30.0 \pm 0.8$ & NS \\
\hline ANOVA & NS & NS & & NS & NS & \\
\hline
\end{tabular}

NSE, neuron specific enolase; ChAT, choline acetyl transferase. 
A

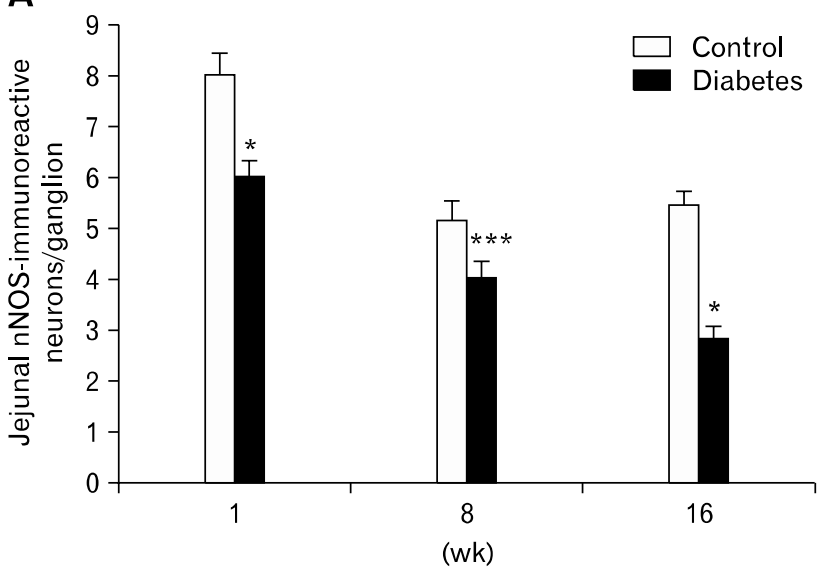

C

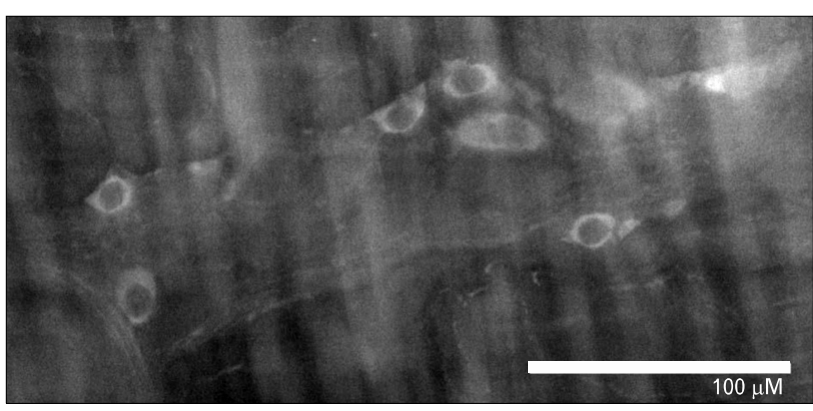

B

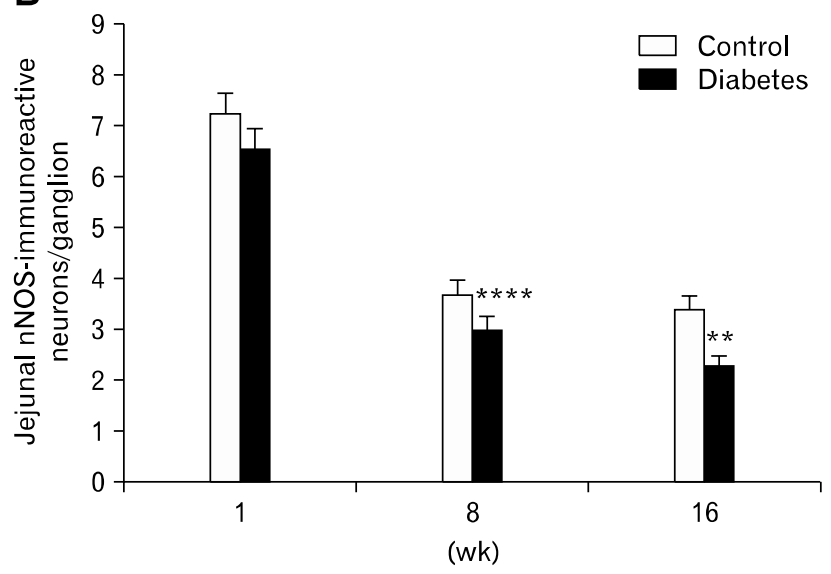

Figure 4. Number of nitrergic (neuronal nitric oxide synthase-immunoreactive $[\mathrm{nNOS}-\mathrm{IR}]$ ) neurons per ganglion in the antrum (A) and jejunum (B) in diabetic and sex- and age-matched control rats at 1,8 and 16 weeks after onset of diabetes. Over time, antral nNOS-IR decreased significantly in both groups. Counts of nNOS myenteric neurons were lower in diabetic than in control animals at every time point. In the myenteric plexus of the jejunum, nNOS-IR decreased significantly over time in both diabetic and control animals. In diabetic animals, nNOS-IR was significantly decreased at week 8 and 16 compared with control. ${ }^{*} P$ $<0.001,{ }^{* *} P<0.01,{ }^{* *} P<0.05,{ }^{* * * *} P=0.05$ compared with control at each time points. (C) Representative image of nNOS-IR neurons in 8 week diabetic rat. Scale bar $=100 \mu \mathrm{m}$.

ing is at variance with several studies reporting delayed gastric emptying in diabetic animals. ${ }^{8,9,23}$ However, most of these studies were done in the streptozotocin or non-obese diabetic (NOD) models, and they used liquid meals or non-nutrient solids to measure emptying rate. ${ }^{8,9,23}$ As the control of liquid emptying depends strongly on nitrergic control of pyloric motor function, ${ }^{9,35,36}$ it is conceivable that liquid emptying is differentially affected by diabetic neuropathy. One of the main functions of nitrergic nerves in the stomach, proximal to the pylorus, is to mediate gastric accommodation to ingestion of a meal. ${ }^{37}$ In human, impaired accommodation is not associated with changes in gastric emptying. ${ }^{38,39}$ Hence, assessment of proximal stomach motor function, and especially meal-induced accommodation, could be considered in future studies in the diabetic BB rat model. As gastroparesis in man is mostly observed in type 1 diabetics with a long-standing disease history, we cannot rule out the occurrence of gastric emptying disturbances with longer follow-up, beyond 16 weeks diabetes in the $\mathrm{BB}$ rat model.

In the small intestine, we found EMG alterations, with a progressively decreasing number of phases 3 and a progressive lengthening in interval of phases 3 , and a decreased proportion of 
adequately propagated activity fronts in diabetic rats. In streptozotocin induced diabetes, a lengthening of the cycle interval and a decrease of phases 3 have been reported as early as 4 days after the onset of diabetes. ${ }^{12,13}$ These alterations in small bowel motility control are likely to be related to decreased nitrergic neuronal activity in the enteric nervous system. Indeed, we previously reported that NOS-inhibition by a 3-day oral administration of L-NG-nitroarginine methyl ester (L-NAME) induced changes on small intestinal EMG similar to those observed in diabetes: a decrease of phases 3 leading to lengthened migrating myoelectric complex cycle and decreased proportion of normally propagated activity fronts. ${ }^{31} \mathrm{We}$ observed similar changes in small bowel motor control and nNOS expression in a rat model of 2,4,6-trinitrobenzene sulfonic acid (TNBS)-induced jejunitis, again supporting a direct relationship between altered motor control and loss of nNOS expression and function. ${ }^{31}$

In our immunhistochemcal studies of myenteric plexus neurons, we found no consistent changes in NSE-IR and ChAT-IR neurons, but diabetic animals had a decreased number of nNOS-IR myenteric neurons in the antrum and jejunum. The finding of decreased nitrergic neuronal numbers confirms previous observations in spontaneous and induced animal models of Type 1 diabetes. ${ }^{9,10,18}$ These changes seem relevant from a pathophysiological perspective, as previous in vitro studies reported decreased nitrergic relaxation of the stomach and small intestine in diabetic animals. ${ }^{9,14,18}$ Similar loss of nitrergic motor control has been reported in the small intestine in aging animals. ${ }^{40} \mathrm{We}$ confirmed altered inhibitory motor control in the small bowel, which can be attributed to loss of nitrergic motor function in the present study and in a previous study on TNBS-induced small bowel dysmotility. $^{31}$

It is unclear whether the decreased nNOS-IR in the present study reflects neuronal loss or altered nNOS expression. Guo et $\mathrm{al}^{16}$ reported increased apoptosis in the myenteric plexus of streptozotocin induced diabetic rats, suggestive of loss of myenteric neurons in this diabetes model. In the present study, we did not detect a reduction in the number of NSE-IR neurons in diabetic animals, potentially arguing against neuronal loss. However, the number of nNOS-IR neurons is small in comparison to the total neuronal count, and it is conceivable that the decrease of nNOS population may not significantly affect the total number of neurons per ganglion.

The mechanism underlying loss of nNOS-IR neurons in the diabetic $\mathrm{BB}$ rat remains to be established. Vagal neuropathy has been proposed as an important contributor to diabetes-associated changes in gastrointestinal motility control, and especially in delayed gastric emptying. ${ }^{3,8,41}$ However, RR-interval variation studies failed to demonstrate cardiac autonomic neuropathy in the cohort of $\mathrm{BB}$ rats in the present study. The finding seems to be at variance with previous studies, ${ }^{23,42,43}$ but it is likely that this is related to the shorter follow-up in our study, as other studies reported altered RR-interval variability after 4 to 6 months. Moreover, although nNOS mRNA expression in the gastric myenteric plexus is under vagal control, neuronal NOS expression in the rat jejunum is independent of the vagus nerve. ${ }^{40}$ Hence, vagal neuropathy is unlikely a mechanism to explain the changes in neural motor control that we observed at 8 and 16 weeks. Hyperglycemia also does not seem to determine these changes, as animals with less or more stringent glycemia control showed similar disturbances.

We did find evidence for a transient inflammatory infiltration at 8 weeks of diabetes, and we hypothesize that this contributed to the changes in neural motor control in the present study. Inflammation of the stomach, small intestine and colon has been reported in $\mathrm{BB}$ rat in the pre- or early diabetic stage. ${ }^{27,28}$ In the colon, this was accompanied by damage to the myenteric and submucosal plexus and impairment of colonic motor function. ${ }^{27}$ The cause of this inflammatory infiltrate is unclear, and it might reflect impaired intestinal barrier function in the diabetic BB rat ${ }^{44}$ or it could be a manifestation of the auto-immune inflammatory processes that are highly prevalent in this animal model. ${ }^{45}$ The finding of transient inflammation followed by a decrease of myenteric nNOS-IR and a loss of inhibitory small intestinal motor control is reminiscent of our findings in TNBS-induced jejunitis. ${ }^{31}$ Transient inflammation may lead to a down-regulation of nNOS through iNOS induction producing large quantities of $\mathrm{NO}^{46,47}$ or through apoptotic cell death. On the other hand, in the present study, the changes in nNOS-IR persisted after resolution of the inflammation. Since several auto-antibodies implicated in diabetes can also be found on neurons, ${ }^{48}$ one could also hypothesize that the intestinal infiltration is of auto-immune origin and contributes to permanent damage to nitrergic neurons. A case report in a diabetic woman, in whom severe gastrointestinal motor disturbances were accompanied by a marked reduction in expression of nNOS and inhibitory peptides on a jejunal biopsy, suggests that similar events may occur in human. ${ }^{49}$

In conclusion, $\mathrm{BB}$ rats display a progressive decrease in nNOS-IR myenteric neurons in the antrum and jejunum. This is not associated with signs of vagal neuropathy or with consistent change in the gastric emptying of semi-solids, but coincides with 
transient inflammation of the gastrointestinal tract. Small intestinal EMG shows abnormalities in inhibitory motor control reminiscent of the effects previously observed after chronic administration of the NOS-inhibitor L-NAME and after transient TNBS-induced inflammation. These observations suggest that diabetic $\mathrm{BB}$ rats have altered intestinal motor control, attributable to loss of nitrergic control and potentially related to transient inflammatory infiltrates.

\section{References}

1. Camilleri M, Malagelada JR. Abnormal intestinal motility in diabetics with the gastroparesis syndrome. Eur J Clin Invest 1984;14: 420-427.

2. Keshavarzian A, Iber FL, Vaeth J. Gastric emptying in patients with insulin-requiring diabetes mellitus. Am J Gastroenterolog 1987;82: 29-35.

3. Itoh $\mathrm{H}$, Yoneda $\mathrm{M}$, Tamori $\mathrm{K}$, et al. Rapid gastric emptying and pathological changes of vagus nerve in the spontaneously diabetic Chinese hamster. Diabetes Res Clin Pract 1995;28:89-95.

4. Pascaud X, Ferre JP, Genton M, Roger A, Ruckebush M, Bueno L. Intestinal motility responses to insulin and glucagon in streptozotocin diabetic rats. Can J Physiol Pharmacol 1982;60:960-967.

5. Asakawa A, Inui A, Ueno N, et al. Ob/ob mice as a model of delayed gastric emptying. J Diabetes Complications 2003;17:27-28.

6. Lincoln J, Bokor JT, Crowe R, Griffith SG, Haven AJ, Burnstock G. Myenteric plexus in streptozotocin-treated rats: neurochemical and histochemical evidence for diabetic neuropathy in the gut. Gastroenterology 1984;86:654-661.

7. Jenkinson KM, Reid JJ. Effect of diabetes on relaxations to non-adrenergic, non-cholinergic nerve stimulation in longitudinal muscle of the rat gastric fundus. Br J Pharmacol 1995;116:15511556.

8. Yamano M, Kamato T, Nagakura Y, Miyata K. Effects of gastroprokinetic agents on gastroparesis in streptozotocin-induced diabetic rats. Naunyn Schmiedebergs Arch Pharmacol 1997;356:145-150.

9. Watkins CC, Sawa A, Jaffrey S, et al. Insulin restores neuronal nitric oxide synthase expression and function that is lost in diabetic gastropathy. J Clin Invest 2000;106:373-384.

10. Wrzos HF, Cruz A, Polavarapu R, Shearer D, Ouyang A. Nitric oxide synthase (NOS) expression in the myenteric plexus of streptozotocin-diabetic rats. Dig Dis Sci 1997;42:2106-2110.

11. Belai A, Lefebvre RA, Burnstock G. Motor activity and neurotransmitter release in the gastric fundus of streptozotocin-diabetic rats. Eur J Pharmacol 1991;194:225-234.

12. Pascaud X, Ferre JP, Genton M, Roger A, Ruckebusch M, Bueno L. Intestinal motility responses to insulin and glucagon in streptozotocin diabetic rats. Can J Physiol Pharmacol 1982;60:960-967.

13. Scott LD, Ellis TM. Small intestinal transit and myoelectric activity in diabetic rats. In: Gastrointestinal motility. Christensen J, ed. New York: Raven Press 1980:395-399.

14. Martinez-Cuesta MA, Massuda H, Whittle BJ, Moncada S. Impairment of nitrergic-mediated relaxation of rat isolated duodenum by experimental diabetes. Br J Pharmacol 1995;114:919-924.
15. Shoham S, Bejar C, Kovalev E, Weinstock M. Intracerebroventricular injection of streptozotocin causes neurotoxicity to myelin that contributes to spatial memory deficits in rats. Exp Neurol 2003;184: 1043-1052.

16. Guo C, Quobatari A, Shangguan Y, Hong S, Wiley JW. Diabetic autonomic neuropathy: evidence for apoptosis in situ in the rat. Neurogastroenterol Motil 2004;16:335-345.

17. Crisá L, Mordes JP, Rossini AA. Autoimmune diabetes mellitus in the BB rat. Diabetes Metab Rev 1992;8:4-37.

18. Takahashi $\mathrm{T}$, Nakamura k, Itoh H, Sima AA, Owyang C. Impaired expression of nitric oxide synthase in the gastric myenteric plexus of spontaneously diabetic rats. Gastroenterology 1997;113:1535-1544.

19. Zandecki M, Vanden Berghe P, Depoortere I, et al. Characterization of myenteric neuropathy in the jejunum of spontaneously diabetic BB-rats. Neurogastroenterol Motil 2008;20:818-828.

20. Talubmook C, Forrest A, Parsons M. Streptozotocin-induced diabetes modulates presynaptic and postsynaptic function in the rat ileum. Eur J Pharmacol 2003;469:153-158.

21. McCann MJ, Stricker EM. Gastric emptying of glucose loads in rats: effects of insulin-induced hypoglycemia. Am J Physiol 1986; 251(3 Pt 2):R609-R613.

22. Green GM, Guan D, Schwartz JG, Phillips WT. Accelerated gastric emptying of glucose in Zucker type 2 diabetic rats: role in postprandial hyperglycemia. Diabetologia 1997;40:136-142.

23. Chang FY, Lee SD, Yeh GH, Wang PS. Influence of blood glucose levels on rat liquid gastric emptying. Dig Dis Sci 1996;41:528-532.

24. Mc Ewen TA, Sima AA. Autonomic neuropathy in BB rat. Assessment by improved method for measuring heart-rate variability. Diabetes 1987;36:251-255.

25. Kuwahara M, Yayou K, Ishii K, Hashimoto SM, Tsubone H, Sugano S. Power spectral analysis of heart rate variability as a new method for assessing autonomic activity in the rat. J Electrocardiol 1994;27:333-337.

26. Aubert AE, Ramaekers D, Beckers F, et al. The analysis of heart rate variability in unrestrained rats. Validation of method and results. Comput Methods Programs Biomed 1999;60:197-213.

27. Meehan CJ, Fleming S, Smith W, Baird JD. Idiopathic megacolon in the BB rat. Int J Exp Pathol 1994;75:37-42.

28. Donegan L, Hardin JA, Gall DG. Mucosal inflammation in a genetic model of type I diabetes. Gastroenterology 1998;114:A967.

29. De Smet B, Depoortere I, Moechars D, et al. Energy homeostasis and gastric emptying in ghrelin knockout mice. J Pharmacol Exp Ther 2006;316:431-439.

30. Rukebusch M, Fioramonti J. Electrical spiking activity and propulsion in small intestine in fed and fasted rats. Gastroenterology 1975;68:1500-1508.

31. Demedts I, Geboes K, Kindt S, et al. Neural mechanisms of postinflammatory dysmotility in rat small intestine. Neurogastroenterol Motil 2006;18:1102-1111.

32. Latour A. Un dispositif simple d'analyse quantitative de l'electromyogramme intestinal chronique. Ann Rech Vet 1973;4:347-353.

33. Bueno L, Praddaude F, Ruckebusch Y. Propagation of electrical spiking activity along the small intestine: intrinsic versus extrinsic neural influences. J Physiol 1979;292:15-26.

34. Krawisz JE, Sharon P, Stenson WF. Quantitative assay for acute intestinal inflammation based on myeloperoxidase activity. Assessment 
of inflammation in rat and hamster models. Gastroenterology 1984; 87:1344-1350

35. Collins PJ, Houghton LA, Read NW, et al. Role of proximal and distal stomach in mixed solid and liquid meal emptying. Gut 1991; 32:615-619.

36. Orihata M, Sarna SK. Inhibition of nitric oxide delays gastric emptying of solid meals. J Pharmacol Exp Ther 1994;271:660-670.

37. Desai KM, Sessa WC, Vane JR. Involvement of nitric oxide in the reflex relaxation of the stomach to accommodate food or fluid. Nature 1991;351:477-479.

38. Tack J, Piessevaux H, Coulie B, Caenepeel P, Janssens J. Role of impaired gastric accommodation to a meal in functional dyspepsia. Gastroenterology 1998;115:1346-1352.

39. Azpiroz F. Control of gastric emptying by gastric tone. Dig Dis Sci 1994;39(12 suppl):18S-19S.

40. Smits GJ, Lefebvre RA. Influence of age on cholinergic and inhibitory nonadrenergic noncholinergic responses in rat ileum. Eur J Pharmacol 1996;303:79-86.

41. Nakamura K, Takahashi T, Taniuchi M, Hsu CX, Owyang C. Nicotinic receptor mediates nitric oxide synthase expression in the rat gastric myenteric plexus. J Clin Invest 1998;101:1479-1489.

42. Sanyal SN, Arita M, Ono K. Inhomogeneous derangement of cardiac autonomic nerve control in diabetic rats. Circ J 2002;66:283-
288.

43. Zhang WX, Chakrabarti S, Green DA, Sima AA. Diabetic autonomic neuropathy in BB rats and effect of ARI treatment on heart-rate variability and vagus nerve structure. Diabetes 1990;39:613-618.

44. Watts T, Berti I, Sapone A, et al. Role of the intestinal tight junction modulator zonulin in the pathogenesis of type I diabetes in BB diabetic-prone rats. Proc Natl Acad Sci USA 2005;102:2916-2921.

45. Malaisse WJ, Courtois P, Scott FW. Insulin-dependent diabetes and gut dysfunction: the BB rat model. Horm Metab Res 2004;36:585594.

46. De Alba J, Cárdenas A, Moro MA, et al. Down-regulation of neuronal nitric oxide synthase by nitric oxide after oxygen-glucose deprivation in rat forebrain slices. J Neurochem 1999;72:248-254.

47. Zandecki M, Raeymaekers P, Janssens J, Tack J, Vanden Berghe P. The effect of nitric oxide donors on nitric oxide synthase-expressing myenteric neurones in culture. Neurogastroenterol Motil 2006;18: 307-315.

48. Schranz DB, Lenmark A. Immunology in diabetes: an update. Diabetes Metab Rev 1998;14:3-29.

49. He CL, Soffer EE, Ferris CD, Walsh RM, Szurszewski JH, Farrugia G. Loss of interstitial cells of cajal and inhibitory innervation in insulin-dependent diabetes. Gastroenterology 2001;121: 427-434. 